\title{
TFIID sequence recognition of the initiator and sequences farther downstream in Drosophila class II genes
}

\author{
Beverly A. Purnell, Peter A. Emanuel, and David S. Gilmour \\ Department of Molecular and Cell Biology, Center for Gene Regulation, Pennsylvania State University, University Park, \\ Pennsylvania 16802 USA
}

\begin{abstract}
Immunopurified TFIID produces a large DNase I footprint over the hsp70, hsp26, and histone H3 promoters of Drosophila. These footprints span from the TATA element to a position $\sim 35$ nucleotides downstream from the transcription start site. Using a "missing nucleoside" analysis, four regions within the three promoters have been found to be important for TFIID binding: the TATA element, the initiator, and two regions located $\sim 18$ and 28 nucleotides downstream of the transcription start site. On the basis of the missing nucleoside data, the initiator appears to contribute as much to the affinity as the TATA element. However, there is weak conservation of the sequence in this region. To determine whether a preferred binding sequence exists in the vicinity of the initiator, the nucleotide composition of this region within the hsp 70 promoter was randomized and then subjected to selection by TFID. After five rounds of selection, the preferred sequence motif-G $/ A / T$ C/T AT/G T G_emerged. This motif is a close match to consensus sequences that have been derived by comparing the initiator region of numerous insect promoters. Selection of this sequence demonstrates that sequence-specific interactions downstream of the TATA element contribute to the interaction of TFIID on a wide spectrum of promoters.
\end{abstract}

[Key Words: TFIID; transcription; Drosophila; $h s p 70$; initiator]

Received December 17, 1993; revised version accepted January 28, 1994.

TFIID is the first general transcription factor that binds to a class II gene promoter prior to transcription initiation. TFIID, in turn, provides a foundation for assembling the initiation complex and is required for activatordependent transcription (Dynlacht et al. 1991; Pugh and Tjian 1991; Hoey et al. 1993). TFIID is a polypeptide complex composed of the TATA-binding protein (TBP) and TBP-associated factors (TAFs) (Pugh and Tjian 1992). Promoter recognition by TFIID has been thought to occur primarily through the binding of TBP to the TATA element (Hahn et al. 1990), a sequence motif located 30 bp upstream of the transcription start site in higher eukaryotes (Breathnach and Chambon 1981). However, many class II genes lack a discernible TATA element (Pugh and Tjian 1991). In these promoters, a sequence around the transcriptional initiation site, called the initiator element, is essential for transcriptional activity in vitro (Smale and Baltimore 1989). It is not known how the initiator element functions in the transcription process. Recent studies have implicated several proteins in binding the initiator. Three mammalian proteins have been purified and cloned that bind to this region and stimulate transcription in reconstituted reactions (Roy et al. 1991; Seto et al. 1991; Du et al. 1993). In addition, in the absence of any other factors, purified RNA polymerase shows some preference for starting transcription within the initiator, suggesting that some specificity may be intrinsic to RNA polymerase II /Carcamo et al. 1991). It has also been suggested that because the initiator is functionally similar to the TATA element in mediating $\mathrm{Spl}$ activation in a reconstituted transcription reaction, the initiator may be recognized by TFIID itself (Smale et al. 1990; Smale 1994).

Studies within our laboratory support the latter hypothesis. Using a crude protein fraction, we demonstrated initially that a TBP-containing complex makes sequence-specific contacts at the TATA element, initiator, and regions farther downstream (Purnell and Gilmour 1993). More recently, in a 3 ' deletion study, we discovered that the affinity of immunopurified TFIID for the $h s p 70$ heat shock gene promoter from Drosophila depends on the TATA element and specific-sequence elements located downstream from the TATA element (Emanuel and Gilmour 1993). For this analysis, TFIID was immunopurified with antibody against the TBP subunit and immobilized with protein A-Sepharose. Deletion in the region between +33 and +10 of the $h s p 70$ promoter reduced the affinity for the immobilized TFIID by approximately eightfold. Several contacts were implicated because deletion breakpoints that fell within the region between +33 and +10 resulted in intermediate reductions in affinity. In addition, it appeared that con- 
tact near the initiator was important because a point mutation at -2 caused a modest reduction in affinity and deletion of sequences downstream of -3 caused a significant reduction in affinity. Together, these results suggested that multiple sequence elements located downstream of the TATA element are recognized by TFIID.

Here, we assess the general importance of interactions downstream of the TATA element to the binding of immunopurified TFIID. We provide a detailed analysis of the interaction between TFIID and the promoters of three Drosophila genes: hsp70, hsp26, and histone H3. The $h s p 70$ and $h s p 26$ heat shock gene promoters are rapidly induced by heat shock and other stress treatments (Craig 1985; Lindquist 1986). The histone H3 is not induced by heat shock but is transcribed in a cell cycledependent manner during $S$ phase (Anderson and Lengyl 1984). We show that TFIID interacts in a similar manner with all three of these promoters, making contacts at the TATA element, initiator, and +18 and +28 regions. Furthermore, in this study we analyze the contact made by TFIID at the initiator. We reveal that TFIID recognizes a sequence within the context of hsp70 that corresponds to an insect initiator consensus sequence identified by several researchers. This suggests that the initiator functions as a site of recognition by TFIID in a wide spectrum of promoters.

\section{Results}

Immupurified TFIID produces similar DNase I footprints on the hsp70, hsp26, and histone H3 promoters

For the $h s p 70$ promoter, contacts between TFIID and sequences downstream of the TATA element contribute significantly to binding (Emanuel and Gilmour 1993). We were interested in determining whether similar interactions occurred on different promoters. For comparison, we chose to examine two heat shock promoters, $h s p 70$ and $h s p 26$, and the promoter for a non-heat shock gene, histone $\mathrm{H} 3$. The interaction of each promoter was first evaluated by DNase I footprinting. For this analysis, TFIID was isolated from a crude TFIID preparation with monoclonal antibody directed against the TBP subunit. The immune complex was then immobilized on protein G-Sepharose. TFIID immobilized in a similar manner had been shown previously to bind an $h s p 70$ promoter fragment and to produce a DNase I footprint that spanned the region from -44 to +35 (Emanuel and Gilmour 1993).

Figure 1 shows that immobilized TFIID produced very similar DNase I footprints on both the heat shock and histone promoters. These footprints extended from the TATA element to a region $\sim 35$ nucleotides downstream of each transcription start site. A similar pattern of
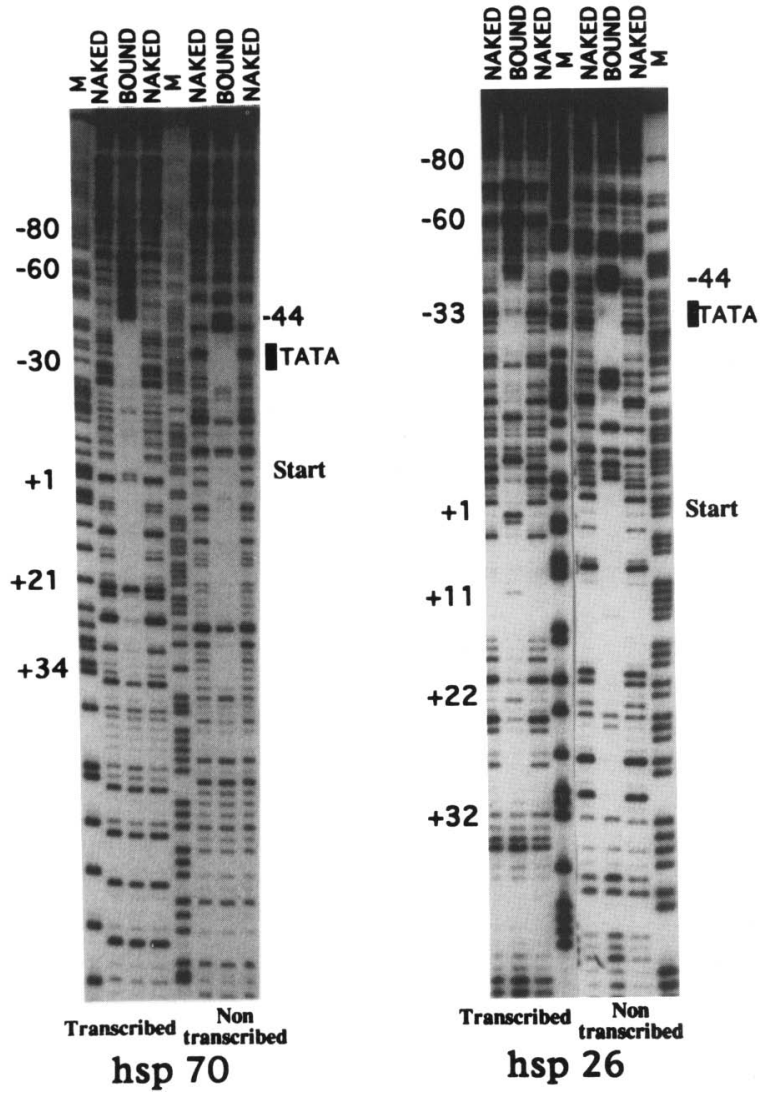

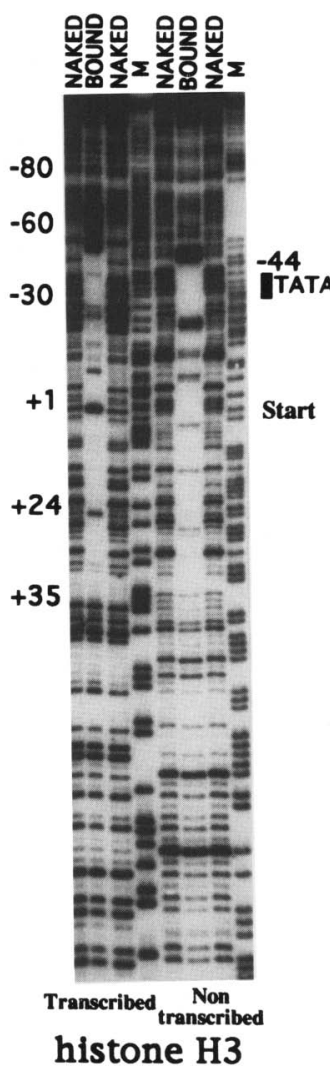

Figure 1. DNase I footprints on $h s p 70$, hsp26, and histone H3. TFIID immunopurified with an anti-TBP monoclonal antibody was allowed to bind three promoter fragments labeled on either the nontranscribed or transcribed strand. After removal of the unbound material, the immobilized complexes were briefly digested with DNase I (lanes labeled BOUND). Control digestions were performed with DNA incubated with protein G-Sepharose alone (lanes labeled NAKED). The following DNA fragments were used. The BamHI-HindIII fragment of $h s p 70$ spans the region from -190 to +89 . The ApaLIHindIII fragment of $h s p 26 \mathrm{~S} / \mathrm{X}$ spans the region from -118 to +47 . The AvaIEcoRI fragment of $\mathrm{H} 3$ spans the region from -131 to +119 . For each promoter fragment, the transcribed strand was labeled using polynucleotide kinase and the nontranscribed strand was labeled by filling in with Klenow. Numbers are relative to the transcription start site of +1 . 
DNase I cutting was produced by impure TFIID, which was free in solution (Gilmour et al. 1990; Emanuel and Gilmour 1993; data not shown). An interesting region of DNase I hypersensitivity extended as much as 70 nucleotides upstream of the transcription start ste. This was most evident on the transcribed strand. These results suggest that TFIID makes comparable contacts on the three promoters in the region from -70 to +35 .

The footprint produced on the $h s p 70$ promoter in Figure 1 was identical to the footprint produced when TFIID was purified and immobilized by a polyclonal antibody against TBP (Emanuel and Gilmour, 1993). To determine whether monoclonal antibody immobilized the same protein complex as polyclonal antibody, the monoclonal immunoprecipitate was analyzed on an SDS-polyacrylamide gel. Figure 2 (lane 1) shows that the most prominent polypeptides found in the immunoprecipitate, other than the antibody itself, had sizes of $110,80,60$, and $40 \mathrm{kD}$. These polypeptides match the sizes of TAFs that had been identified previously as subunits of TFIID

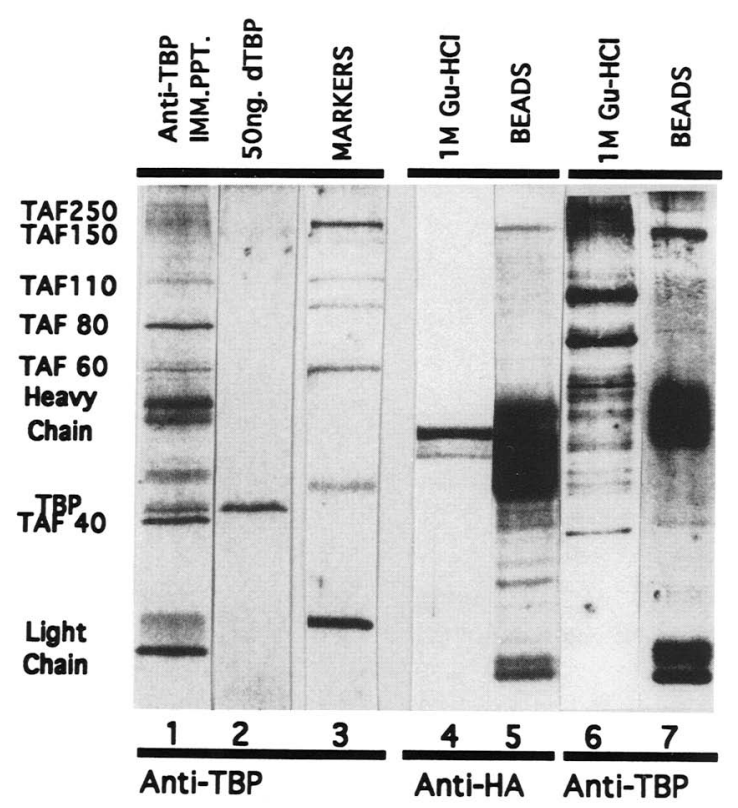

Figure 2. Polypeptide composition of the anti-TBP immunoprecipitates. SDS-PAGE analysis of immunoprecipitates; (Lane 1) Immunoprecipitate from $50 \mu \mathrm{l}$ of $0.5 \mathrm{M}$ phosphocellulose fraction performed with monoclonal 14C2-F4 against TBP; (lane 2) $50 \mathrm{ng}$ of recombinant TBP prepared as described previously (Emanuel and Gilmour 1993); (lane 3) molecular mass markers of $205,116,97.4,66,45$, and $29 \mathrm{kD}$; (lane 4) polypeptides eluted with $1 \mathrm{M}$ guanidine- $\mathrm{HCl}$ from an immunoprecipitate generated with monoclonal 12CA5-I against the influenza HA epitope (negative control); (lane 5) polypeptides remaining associated with the protein G-Sepharose after elution of the 12CA5-I immunoprecipitate with $1 \mathrm{M}$ guanidine- $\mathrm{HCl}_{\text {; }}$ (lane 6) polypeptides eluted with $1 \mathrm{M}$ guanidine- $\mathrm{HCl}$ from an immunoprecipitate generated with monoclonal 14C2-F4 against TBP; (lane 7) polypeptides remaining associated with the protein G-Sepharose after elution of the 14C2-F4 immunoprecipitate with $1 \mathrm{M}$ guanidine- $\mathrm{HCl}$.
(Dynlacht et al. 1991) and that had been observed previously in our immunoprecipitate with polyclonal antibody (Emanuel and Gilmour 1993). TAF 150 and TAF 250 were not readily apparent. Their staining with silver has been inconsistent, an observation that is similar to that of others (cf. Dynlacht et al. 1991 and Weinzierl et al. 1993).

Previous reports had shown that treatment of immunoprecipitated TFIID with $1 \mathrm{M}$ guanidine- $\mathrm{HCl}$ would elute the TAFs from the complex and TBP would remain bound to the antibody. We treated the immunoprecipitate with guanidine- $\mathrm{HCl}$ and analyzed the eluted proteins (Fig. 2, lane 6). TAFs of $110,80,60$, and $40 \mathrm{kD}$ were clearly evident in the eluted fraction. A monoclonal antibody against an unrelated antigen failed to precipitate any of these polypeptides (Fig. 2, lane 4).

Missing nucleoside analysis of TFIID reveals similar patterns of contact on the hsp 70 , hsp26, and histone $\mathrm{H} 3$ promoters

DNase I footprinting indicated that the interaction of TFIID with these promoters is quite similar. To investigate the similarities more rigorously, we used a variation of the "missing nucleoside" technique of Hayes and Tullius (1989). Hydroxyl radical treatment of an end-labeled DNA fragment removed nucleosides from random positions in the fragment. The extent of the reaction was limited so that an average of $<1$ nucleoside was removed per DNA molecule. This "punctured" DNA was then mixed with immobilized TFIID. If the missing nucleoside interfered with either the association or stability of the TFIID-DNA complex, then the fragment missing this nucleoside would be depleted from the fraction that bound TFIID. Depletion from the bound fraction was monitored by comparing the bound DNA with a portion of the input DNA or free DNA.

Figure 3 shows the results for the missing nucleoside analysis of TFIID. Input, bound, and free DNA fractions were analyzed on sequencing gels. For each promoter, there is a notable decrease in the intensity of the bands corresponding to four locations on the transcribed strand. Reduced binding occurred when nucleosides were missing from the TATA element, the initiator region, and from positions located $\sim 18$ and 28 nucleotides downstream of the transcription start site. On the nontranscribed strand, there were clearly discernible contacts in the TATA element and the initiator. Isolated regions farther downstream were not clearly evident for this strand, but there did seem to be some contribution to binding as the bands throughout the region from the initiator to +30 in the bound lane appeared to be lighter in appearance than the corresponding bands in the input or free lanes. The similarity in the patterns of missing nucleosides, particularly on the transcribed strand, indicates that the TFIID makes comparable contacts with each of the promoters. These patterns are summarized in Figure 8 , below. 


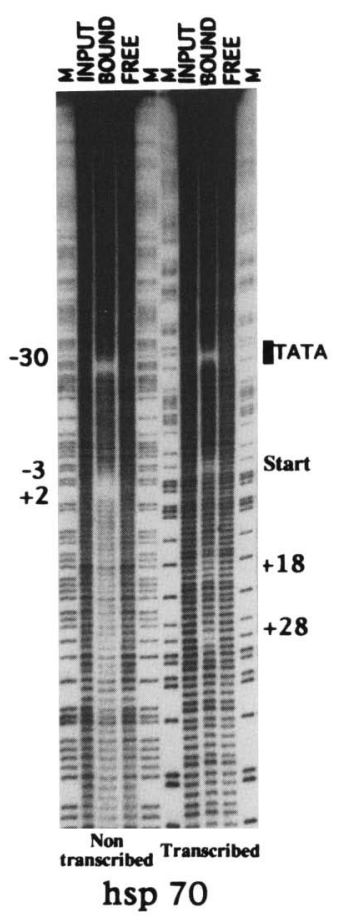

hsp 70

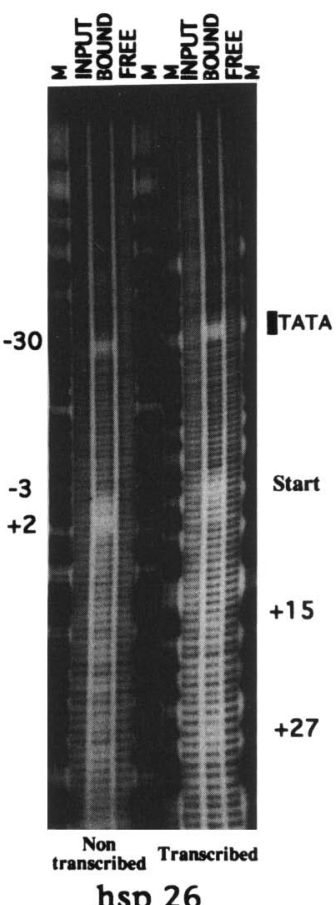

hsp 26

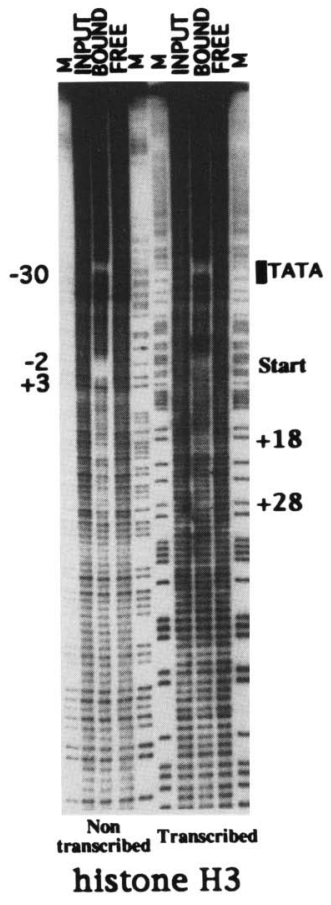

Figure 3. Missing nucleoside analysis of hsp70, hsp26, and histone H3. Immobilized TFIID was presented with hydroxyl radical-modified promoter fragments labeled as described in Fig. 1 and then separated into bound and free fractions. The input, bound, and free material was analyzed on a sequencing gel. Lanes marked $M$ represent $\mathrm{G} / \mathrm{A}$ cleavage patterns.
TFIID selection of preferred binding sequences at the initiator

The missing nucleoside analysis showed that the TATA element and the initiator region contribute equally to the association of TFIID in each promoter. Because the TATA element is highly conserved in these promoters, one might also expect to see sequence conservation in the vicinity of the initiator. Comparison of the sequences for the three promoters, however, reveals little conservation (for a summary of sequences and missing nucleoside patterns, see Fig. 8, below). Several researchers have attempted to determine whether a conserved sequence element resides near the transcription start site of various other genes (Bucher 1990; Cherbas and Cherbas 1993). Through these studies, an initiator consensus sequence motif has been deduced; however, considerable variation from the consensus sequence is observed when individual promoters are then compared with the consensus sequence.

If TFIID recognizes the initiator of many promoters, it might tolerate mismatches from the consensus sequence because of compensatory interactions elsewhere in the promoter (Purnell and Gilmour 1993). To further investigate the relationship between TFIID and the initiator, we determined whether TFIID would select a particular sequence motif from a pool of DNA molecules with randomized initiators. Selection was made by placing the randomized sequence within the $h s p 70$ promoter. In this way, the contribution of the surrounding sequences was held constant. Moreover, it was necessary to perform the selection within the context of the normal surrounding sequences because deletions of the TATA element or of sequences downstream of the initiation site severely reduced the affinity of TFIID for the DNA (Emanuel and Gilmour 1993; Purnell and Gilmour 1993).

To identify the preferred sequences, we used a modified version of the selected and amplified binding (SAAB) procedure of Blackwell and Weintraub (1990). Using synthetic oligonucleotides, we generated a pool of $h s p 70$ derivatives that had random sequences incorporated into the region surrounding the initiator (Fig. 4A). This randomized region corresponded to the region identified by the missing nucleoside analysis. With the exception of this randomized patch and restriction sites at each end of the fragment, the DNA sequence matched that of the hsp70 promoter from just upstream of the TATA element, position -39 , to a point 36 nucleotides downstream of the transcription start site.

The pool was first amplified by PCR. The selection was then performed by incubating the pool of randomized DNA with crude TFIID in the presence of nonspecific competitor DNA and separating the bound and unbound fractions by a mobility retardation assay (Purnell and Gilmour 1993). The bound and unbound fractions of DNA were recovered separately from the gel and then amplified by the polymerase chain reaction (PCR). The sequences of these amplified fractions were determined or the DNA was subjected to additional rounds of selection, as outlined in Figure 4B. Processing the unbound (counter-selected) fraction in parallel with the bound fraction (selected) served as a control to alert us to PCR artifacts such as TFIID-independent selection of a sequence or DNA contamination.

Progress in selection was readily detected by analyzing the amount of radioactive DNA from different rounds of 
Purnell et al.

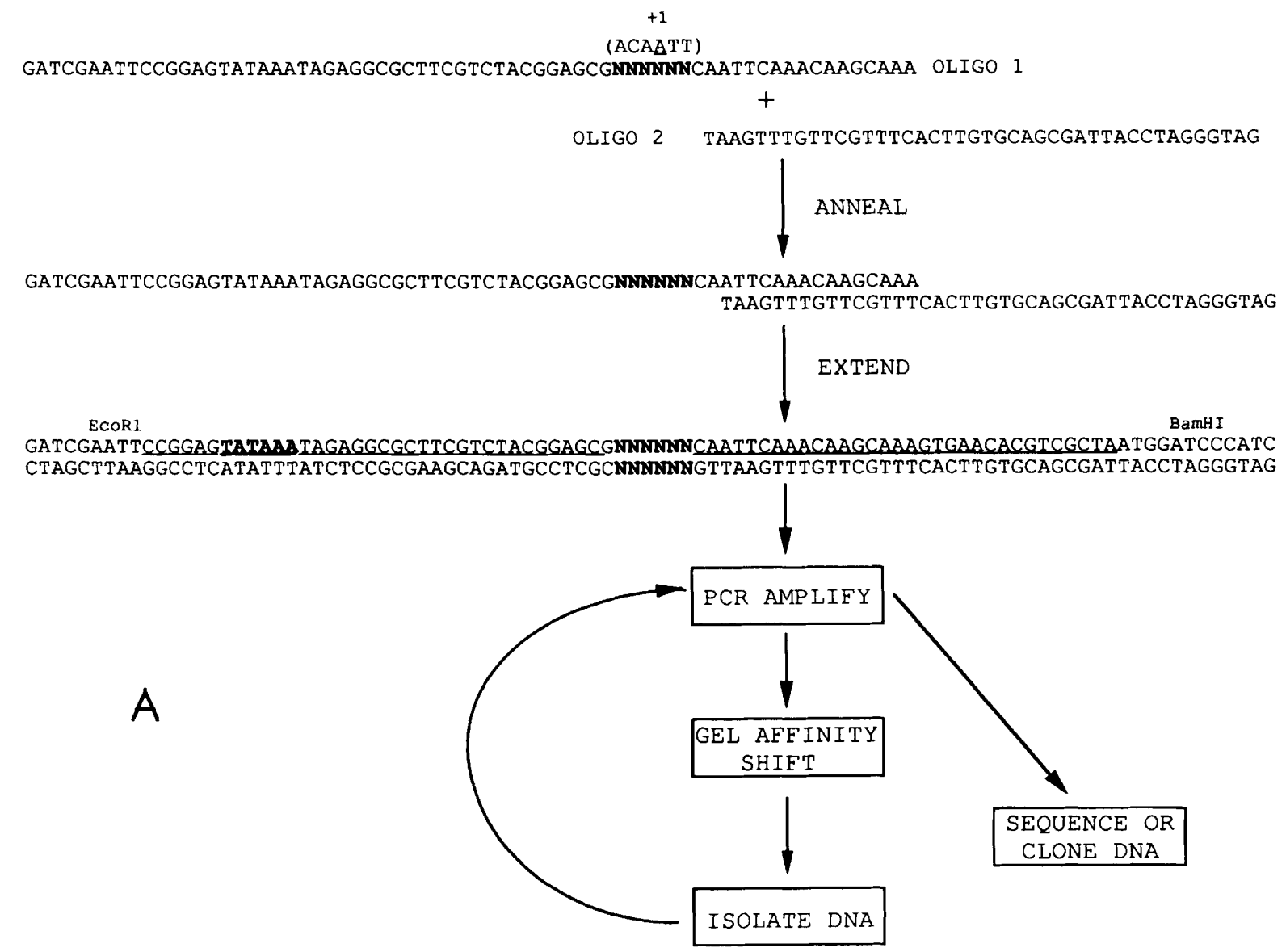

Figure 4. Scheme for identifying the initiator sequence that is preferen. tially bound by TFIID. $\langle A\rangle$ Two oligonucleotides that were synthesized which could be annealed and extended to give the Drosophila hsp70 promoter from position -39 to +36 , relative to the transcription start site, with randomized initiator, and flanking restriction sites that corresponded to primers A and B (see Materials and methods). The 2 oligonucleotides were annealed and then extended with Klenow and dNTPs to give a doublestranded DNA fragment. This DNA was PCR amplified with primers A and $B$ and Taq polymerase, and the DNA was then radioactively end-labeled with kinase and [ ${ }^{32}$ P]ATP. The labeled template $(100,000 \mathrm{cpm})$ was incubated with the phosphocellulose faction that contains TFIID and then subjected to the mobility retardation assay (Purnell and Gilmour 1993). Bound and unbound DNAs were then isolated and amplified by PCR. Amplified DNA was either subjected to additional rounds of selection by TFIID, sequenced, or cloned. The nontranscribed strand of the $h s p 70$ normal sequence is underlined, and the randomized initiator and the TATA element are in bold text. $(B)$ Schematic of DNA fractions isolated from SAAB mobility retardation assays. For each round, selected (represented as B1-B5) and counterselected $(\mathrm{X} 1-\mathrm{X} 5)$ DNAs were isolated. $(\lambda \mid$ Bound fractions; $(\searrow)$ unbound fractions. (O) DNAs that were sequenced in Fig. 6.

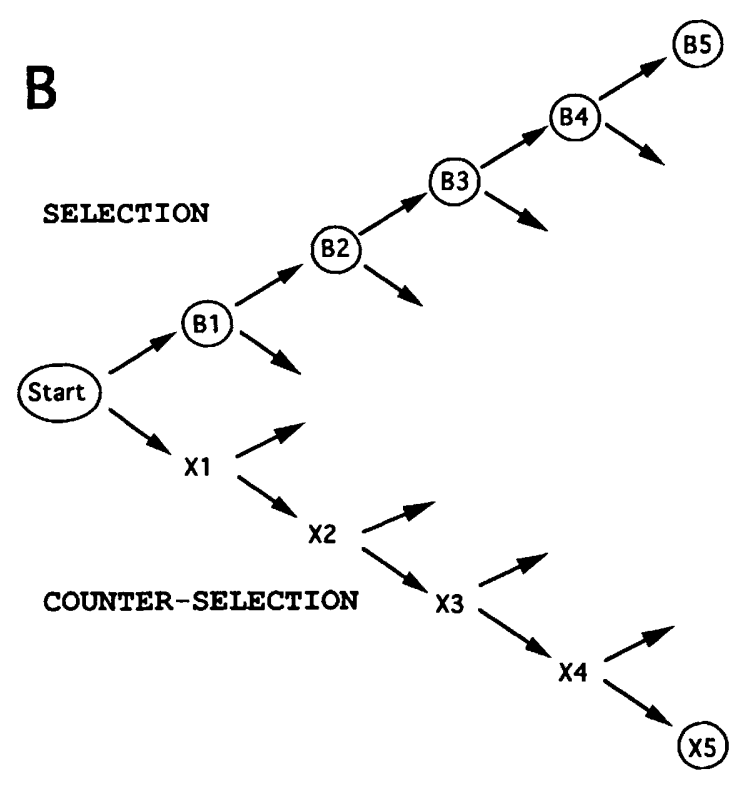

selection that mobility-shifted in the binding assay with TFIID (Fig. 5A). At round 2, the amount of radioactive DNA in the bound fraction was greater than that of the start material but considerably less than the fifth round of selection. Furthermore, on comparing the fifth round counterselection (X5) and selection (B5), a ninefold dif- ferential in binding was observed, strengthening the contention that TFIID had selected a preferred binding sequence from the randomized pool.

The SAAB analysis was carried out with a crude TFIID fraction (phosphocellulose $0.5 \mathrm{~m}$ fraction) because it provided better separation of bound and unbound DNA than 


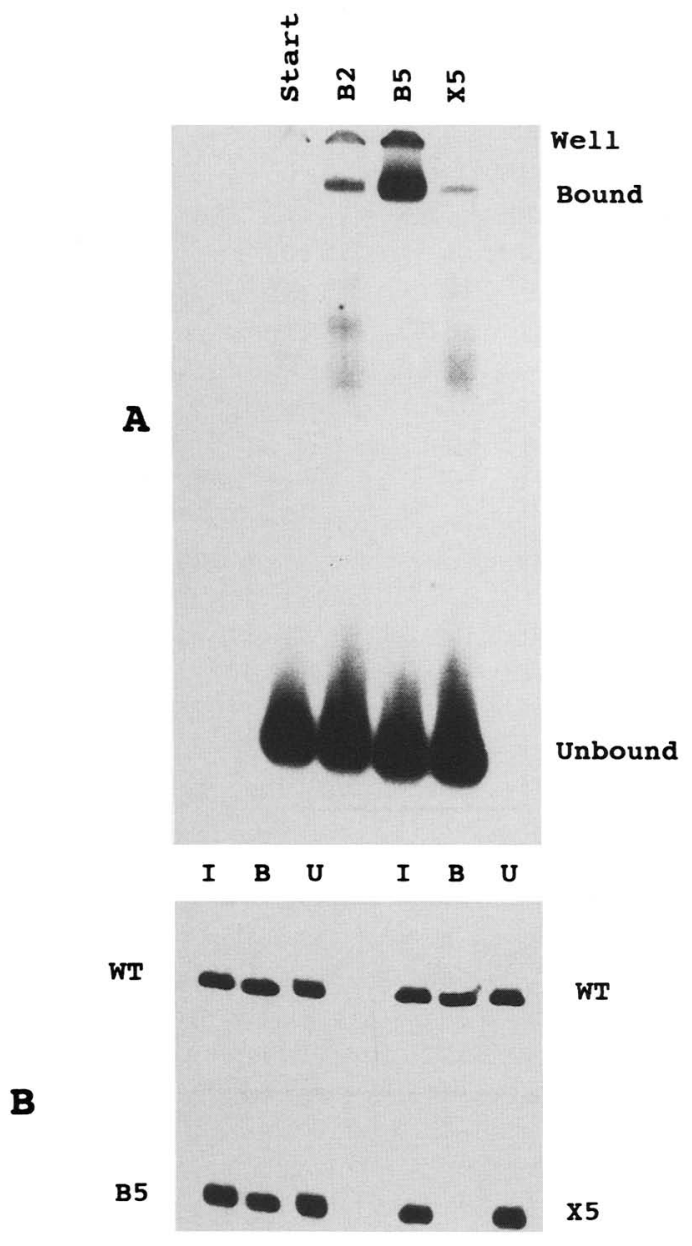

Figure 5. TFIID shows high affinity for DNA that has been subjected to positive selection. (A) Mobility retardation assay of selected and counterselected DNAs upon incubation with TFIID fraction. End-labeled DNA from pools start, B2, B5, and X5 (see Fig. 4B) were gel-shifted with the crude TFIID fraction (phosphocellulose fraction). $(B)$ Binding of end-labeled DNA to immunopurified TFIID. Two input (I) mixtures of DNA were prepared by combining an end-labeled $h s p 70$ promoter fragment of natural sequence composition spanning from -50 to +89 (WT) with either end-labeled pools of B5 or X5 DNA (see Fig. 4B). Each mixture was then incubated with immobilized TFIID, separating the DNA into bound $(B)$ and unbound $(U)$ fractions. Equal amounts of radioactive material recovered from the bound (B), unbound (U), and input (I) DNA were analyzed on a sequencing gel.

did the immunopurified TFID; hence, a lower degree of background binding could be achieved. This approach should be a valid way to identify the preferred binding site of TFIID, because the missing nucleoside patterns that were observed with immunopurified TFIID were identical to the missing nucleoside patterns observed for the mobility-shifted complex formed with crude TFIID (cf. Fig. 3, this paper, with Fig. 4, Purnell and Gilmour 1993). We evaluated the approach by determining whether the selected and counterselected pools of DNA from the fifth round exhibited the same relative affini- ties with both crude TFID (Fig. 5A) and immunopurified TFIID (Fig. 5B). Immunopurified TFIID was presented with a radiolabeled pool of either selected (B5) or counterselected (X5) DNA. A radiolabeled fragment from the wild-type $h s p 70$ promoter (WT) of a different length was included as a positive internal control. The bound and unbound fractions of DNA were isolated and then analyzed on a sequencing gel. As shown in Figure $5 B$, the selected DNA bound significantly better than the counterselected DNA (cf. lanes 2 and 5), as was the case with crude TFIID and the mobility retardation assay (Fig. 5A).

\section{Identification of the initiator sequence that is preferentially bound by TFIID}

To identify the sequence preferentially bound by TFIID, we first sequenced the PCR-amplified DNAs that had been selected from round 1 through round 5 (Fig. 6A). As expected, the starting material contained all 4 nucleotides present in approximately equal proportions at the

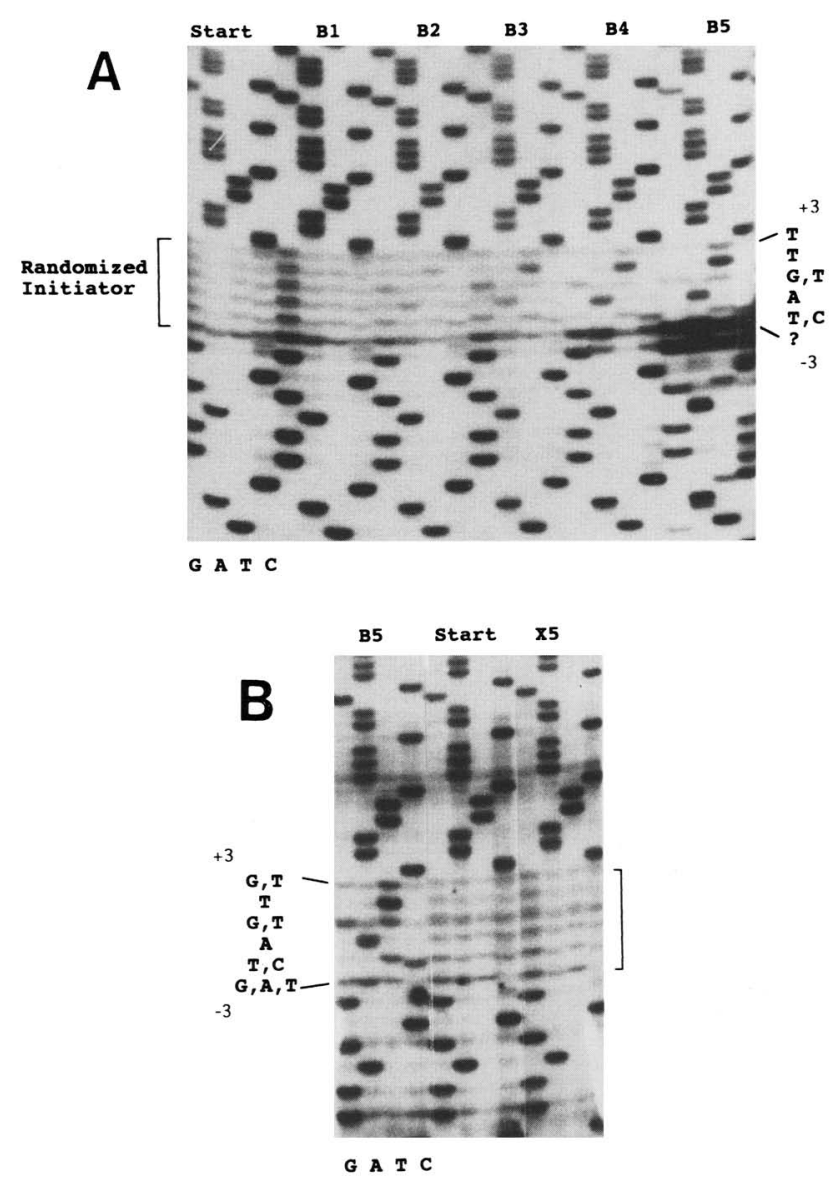

Figure 6. Sequence analysis of TFIID-selected DNA pools. $(A)$ Sequences of the starting templates and B1-B5 pools. From left to right for each pool, the sequencing lanes correspond to $G, A$, $T$ and $C .(B)$ Same as $A$ for starting template and fifth round selected (B5) and counterselected (X5) DNA pools. The initiator sequence deduced from B5 is indicated next to the autoradiograph. 
six positions around the start site. Within two rounds of selection, a preferred sequence was apparent. This was consistent with the increased level of binding that was observed for the B2 pool over the start pool in the mobility retardation analysis (Fig. 5A). By round 5, preferred nucleotides at each position within the random region were evident (Fig. 6A,B). A conservative assessment of the sequence found in round 5 suggests that the preferred sequence on the nontranscribed strand is $G / A / T$ T/C $A$ $\mathrm{G} / \mathrm{T} \mathrm{T} / \mathrm{T}$. Upon sequencing the counterselected material from round 5, it was apparent that this sequence was essentially identical to the start site material (Fig. 6B, lane labeled X51.

Because it was difficult to produce the four sequencing reactions at uniform intensities, some uncertainty remained in identifying the preferred binding site from the sequence of the selected pool. To overcome this uncertainty, we cloned the selected pool and sequenced 12 representatives. A tabulation of these sequences is shown in Figure 7. The consensus sequence consisting of $\mathrm{G} / \mathrm{A} / \mathrm{T} / \mathrm{T}$ A $\mathrm{G} / \mathrm{T} \mathrm{T} \mathrm{G}$ was deduced and shows excellent agreement with the sequence deduced from the PCR-amplified pool from round 5 (Fig. 6). Strong selection is observed for five of the six positions that had been randomized. The relationship between the sequence se-

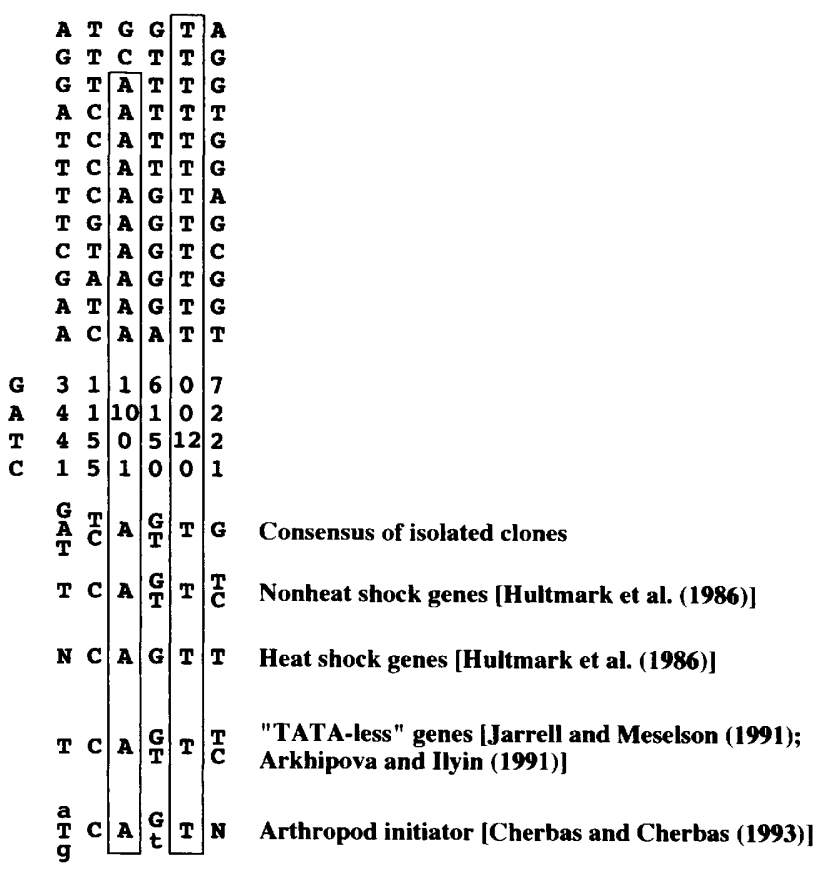

Figure 7. Tabulation of B5 isolated clones and initiators deduced from sequence comparisons. The top 12 sequences are derived from isolated clones of the B5 pool. This is followed by a tabulation of base frequencies in these 12 clones. From the base frequencies, a consensus has been derived as the preferred binding site for TFIID. This is compared with the consensus sequences that different investigators have deduced by comparing the sequences near the transcription start site of various classes of promoters. lected by TFIID and the conserved initiators listed at the bottom of Figure 7 is discussed later.

\section{Discussion}

Sequences from the transcription start site to +35 make significant contributions to the transcriptional activity of a variety of Drosophila promoters. Using P-elementmediated transformation as an assay for in vivo activity, $3^{\prime}$ deletions with breakpoints between the initiation site and +35 were found to reduce significantly heat shock induction levels for the $h s p 22$ and the $h s p 70$ promoters (Hultmark et al. 1986; Lee et al. 1992). Deletions in the hsp70 promoter also reduced the level of RNA polymerase II that was paused on the promoter prior to heat shock (Lee et al. 1992). Sequences downstream of the transcription start site have been implicated for numerous other Drosophila genes (Biggin and Tjian 1988; Perkins et al. 1988; Soeller et al. 1988; Arkhipova and Ilyin 1991; Jarrell and Meselson 1991; Fridell and Searles 1992). In light of our findings that sequences in this region contribute to TFIID binding, disruption of the TFIID interaction provides a likely explanation for why these mutations impair promoter activity. Because a recombinant preparation of Drosophila TBP failed to exhibit binding outside of the TATA element of $h s p 70$, other subunits of TFIID, TAFs, are probably responsible for sequence-specific interactions downstream of the TATA element (Emanuel and Gilmour 1993).

When 6 nucleotides around the transcription start site were randomized within the $h s p 70$ promoter, TFIID was found to bind preferentially sequences matching the consensus $G_{/ A} / T T_{/ C} A G_{T} T$ G. Remarkably, this preferred consensus sequence matches quite well with a consensus sequence that other investigators have deduced by comparing the sequences of different classes of Drosophila and other insect promoters (Fig. 7). This match provides compelling support for the hypothesis that sequence-specific interactions between TFIID and the region downstream of TATA element contribute to the transcription process in a wide spectrum of insect promoters. The initiator also may be recognized by TFIID in mammalian cells; the $A$ in position 3 and the $T$ in position 5 of our preferred initiator matches the $A$ at +1 and the $T$ at +3 that were found to be most critical for reconstituting initiator function in a mammalian transcription system (Javahery et al. 1994).

If the sequence at the transcription start site is important for TFIID binding, then one might anticipate finding this sequence in the vicinity of the transcription start sites for the hsp70, hsp26, and histone H3 promoters. Searching the region defined by the missing nucleoside analysis reveals a six out of six match for the histone $\mathrm{H} 3$ promoter (see Fig. 8). However, there is at best a four out of six match found for the hsp70 and hsp26 promoters. This disparity is somewhat disconcerting, particularly because the sequence composition of the preferred binding site already has some ambiguity. A resolution is provided if we consider that multiple contacts might contribute to the binding of TFIID. Numerous sites of con- 


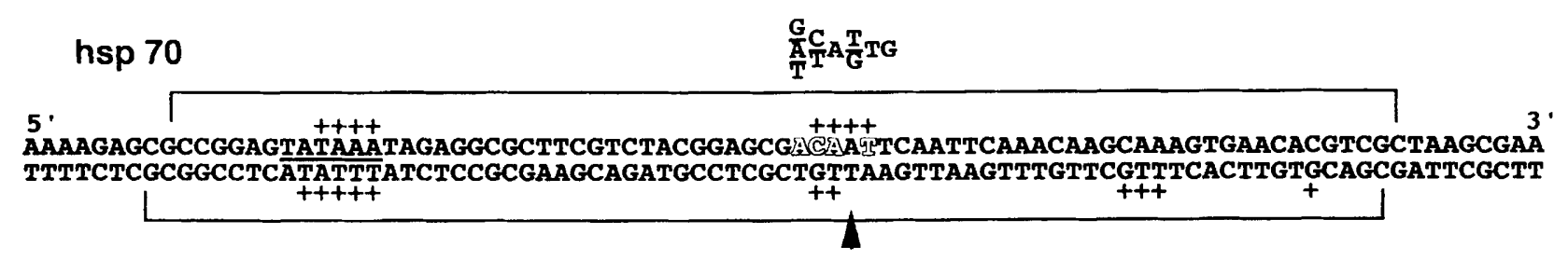

hsp 26

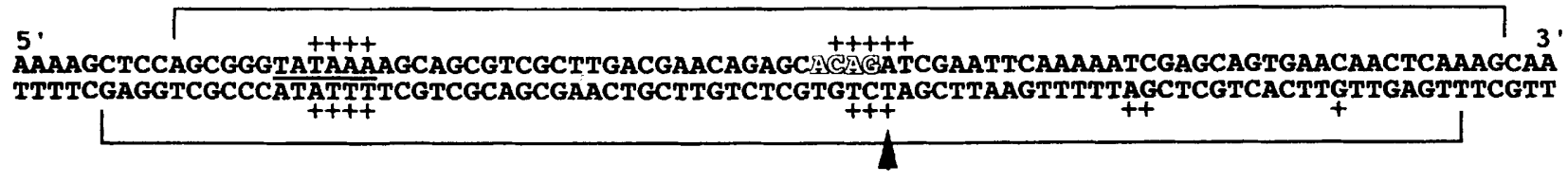

histone $\mathrm{H} 3$

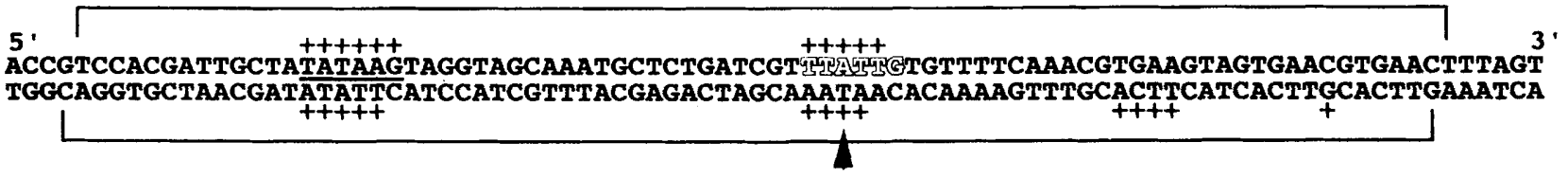

Figure 8. Summary of the TFIID missing nucleoside analysis and DNase I footprinting analysis and correlation of the sequences with deduced TFIID initiator binding sequences. (Top) The consensus sequence corresponding to the initiator that was selected by TFIID (see Fig. 7). The sequences of the hsp $70, h s p 26$, and histone $\mathrm{H} 3$ promoters are below. The top strand of each sequence represents the nontranscribed strand of the promoter. The arrow designates the transcription start site. Energetically important contacts, implicated by hydroxyl radical analysis, are indicated by + above and below the bases. We have not designated the missing nucleoside contacts on the nontranscribed strand downstream of the initiator because no well-defined points of contact were clearly evident for each promoter; instead, there appeared to be small reductions in binding as a result of modifications throughout the region (see Fig. 3). The region of DNase I protection is delimited by horizontal brackets. Using the missing nucleoside pattern as a guide, we have underlined 6 nucleotide stretches that provide a possible match to the preferred TFIID binding sequence. Those nucleotides that match the preferred initiator have been highlighted.

tact could provide TFIID with considerable tolerance in the sequence composition, even in those regions that appear to be most important for binding. Sequence constraints in any one region may be relaxed by strengthened contacts elsewhere. One of the best illustrations of this principle that we have encountered so far comes from a methylation interference analysis of the interaction between TFIID and three different constructs of the hsp70 promoter (Purnell and Gilmour 1993). Methylation interference analysis of the transcribed strand of the normal promoter revealed a weak dependence on a contact at +28 ; no other interference was evident in this assay. In contrast, point mutations in the $h s p 70$ promoter at either the TATA element or the start site resulted in a dramatic change in the methylation interference pattern, displaying a greatly increased dependence on downstream contacts, including +28 . The SAAB analysis may be strongly biased toward an ideal initiator.

Our data clearly establish that in Drosophila the binding of TFIID is strongly influenced by interactions between TFIID and sequences downstream of the TATA element. This point is not clear for TFIID in human cells. Human TFIID contacts the regions downstream of the TATA element on some promoters but not others (Sawadogo and Roeder 1985; Nakajima et al. 1988; Van Dyke et al. 1988; Zhou et al. 1992; Chiang et al. 1993). It remains to be determined whether these differences af- fect binding strengths, because the reported studies with human TFIID have been done with saturating levels of TFIID. The function of sequences around the transcription start site in mammalian cells has become particularly confusing because several factors appear to recognize DNA sequences in this region (Roy et al. 1991; Seto et al. 1991; Du et al. 1993). These factors seem to be distinct from TFIID, and homologous proteins have not yet been found in Drosophila. One of the factors, TFII-I, has been shown to increase the level of recombinant TBP that associates with DNA, and the contribution of TFII-I depends on the sequence of the initiator (Roy et al. 1993). The contribution of TFII-I to binding can be replaced by the general transcription factor TFIIA (Roy et al. 1991). However, with TFIIA there is no longer a dependence on the sequence of the initiator. These observations lead to the proposal that there may be alternative pathways for recruiting TFIID to the promoter (Roy et al. 1993). In Drosophila, sequence recognition by the TAFs may provide yet another pathway, which is commonly used for many promoters.

TFIID is one of the first components to interact with the promoter during assembly of a transcription complex (Zawel and Reinberg 1993). The overlap between some TFIID contacts and the site of transcriptional initiation suggests that these interactions may function directly in the initiation process, such as in positioning the active 
site of RNA polymerase II or the unwinding of DNA. Currently, we have no experiments that address whether the TFIID participates in the unwinding of the DNA. The available data do, however, seem to indicate that it is unlikely that the TAF contacting the start site sequence directly positions RNA polymerase II. We have found that increasing the spacing between the TATA element and the start site sequence by 2 nucleotides causes the major start site to shift 2 to 3 nucleotides upstream of the normal start (Purnell and Gilmour 1993). In contrast, hydroxyl radical interference analysis indicates that the interaction of TFIID with the initiator moves downstream to maintain contact with the original initiator sequence. Further evidence against the initiator directing the position of the start site comes from the analysis of a TATA-less promoter in a mammalian in vitro transcription system. For a test plasmid containing only an Spl-binding site and an initiator, the position of the start site shifted when different dinucleotides were used to prime transcription (Zenzie-Gregory et al. 1992). The efficiency of initiation was not significantly altered by the different dinucleotides.

We suggest that the multiple sequence elements in the promoter that are recognized by TFIID might significantly influence transcription levels by three mechanisms. These are the recruitment of TFIID to the promoter, its retention on the DNA, and its conformation on the promoter.

In the first mechanism, we envision that the TAFs may interact with the downstream sequences, bringing TBP into position so that it can associate with the TATA element. TBP might be housed in the Drosophila TFIID complex in a way that inhibits DNA binding until certain TAF-DNA interactions occur. This could explain why a $3^{\prime}$ deletion of the $h s p 70$ promoter, which had its breakpoint at -3 but retained the TATA element, bound very poorly to immobilized TFIID and to TFIID free in solution (Emanuel and Gilmour 1993). This mechanism resembles class I and class III genes. For class I genes, TBP is part of a complex called SL1 (Comai et al. 1992). The binding of SL1 with the promoter is greatly enhanced by a factor called UBF (Bell et al. 1989; Pikaard et al. 1989). Recent analysis shows that the binding of UBF and its conformation on the DNA are strongly influenced by sequences in the region between +17 and +32 (Lablanc et al. 1993). In addition, there appear to be partially redundant contacts made from -20 to +60 . For class III genes, TBP enters the transcription pathway as a subunit of TFIIIB (Kassavetis et al. 1992; Taggart et al. 1992; White and Jackson 1992). The best-characterized class III gene is that of a yeast tRNA gene (Kassavetis et al. 1992), where TFIIIB alone does not recognize the promoter. Another factor, TFIIIC, binds to sequence motifs downstream of the transcription start site (Kassavetis et al. 1990). Protein-protein interactions between TFIIIC and TFIIIB serve to recruit TFIIIB to the promoter. By analogy to this mechanism, the TFIID complex could be viewed as a stable union of TBP and components that recognize intragenic sequences into a single complex.

Promoter strength will also depend on the retention of
TFIID. We have found that the affinity of TFIID is strongly influenced by the contribution of downstream interactions (Emanuel and Gilmour 1993). However, these contacts must be disrupted or altered, at least transiently, as the RNA polymerase initiates and elongates through this region (Van Dyke et al. 1988; Buratowski et al. 1989). At this stage in the transcription pathway, the retention of TFIID may become largely dependent on the TATA element. This could be analogous to the yeast tRNA gene. In vitro, the retention of TFIIIB does not seem to require the persistent association of TFIIIC (Kassavetis et al. 1990; Bartholomew et al. 1993). Once TFIIIB has been recruited in a TFIIIC-dependent manner, the TFIIIC can be stripped away from the downstream region with high salt or heparin and the remaining TFIIIB can mediate multiple rounds of initiation. Cross-linking analysis shows that even without salt displacement, the association of RNA polymerase III disrupts certain contacts of TFIIIC (Bartholomew et al. 1993). It seems that the downstream contacts of TFIID are looser than TATA contacts, because the DNase I footprint of TFIID, which normally spans the region from -44 to +35 , shrinks down to a footprint that is localized over the TATA element when the salt concentration is raised from 90 to $300 \mathrm{~mm}$ (Sypes and Gilmour 1994).

Many of the most highly transcribed promoters contain the sequence TATAAA. As a high-affinity site for TBP, this could allow TFIID to remain associated with the promoter and mediate multiple rounds of initiation. This would seem essential for the $h s p 70$ and $h s p 26$ genes as an initiation event occurs every 2 to $4 \mathrm{sec}$ on the active genes (Vazquez et al. 1993). Deviation from this high-affinity TATA sequence may reduce retention of TFIID, thereby reducing transcription levels. This could help to reconcile two opposing views that have emerged with respect to the rounds of initiation that can be mediated by TFIID. Early experiments indicated that TFIID formed a stable complex with the adenovirus major late (AdML) promoter that might mediate multiple rounds of initiation (Hawley and Roeder 1987; Van Dyke et al. 1988). Subsequent studies with Drosophila promoters lead to a different model in which all remnants of a preinitiation complex dissociated from the template with each round of initiation (Kadonaga 1990). The AdML promoter contained a TATAAA sequence element, but neither of the Drosophila promoters contained a sequence similar to this. Therefore, the TBP contact on the Drosophila promoter may have been too weak to retain the TFIID complex when the initiation complex disrupted downstream contacts of TFIID.

The conformation of the protein-DNA complex might impact significantly on transcription levels. This conformation could be strongly influenced by the DNA sequence contacted by TFIID. The DNase I footprint provides one view of the TFIID conformation. We have recently analyzed the footprint that TFIID makes on an hsp26 mutant containing the change TATA to CCCA (Q. Lu, L. Wallrath, P. Emanuel, S. Elgin, and D. Gilmour, in prep). This mutation causes a 30 -fold reduction in the transcriptional activity in vivo but a much smaller 
decrease in the affinity for purified TFIID. There is, however, a dramatic difference in the appearance of the DNase I footprints formed on the normal and mutant promoters, suggesting that the large decrease in transcription could be a result of disturbances in the spatial organization of the components assembling on the promoter. Cocrystals of TBP and DNA reveal that the TATA sequence is bent at a $100^{\circ}$ angle ( Kim et al. 1993a,b), so disruption of this interaction could greatly alter the molecular architecture of the promoter.

We are also intrigued by the similarity between the TFIID DNase I footprints that we find on the hsp 70, hsp26, and histone $\mathrm{H} 3$ promoters (Fig. 1) and the footprints of human TFIID that form on the adenovirus E4 promoter in the presence of the transcriptional activator ATF (Horikoshi et al. 1988). Human TFIID produces a small footprint on the E4 promoter that is localized to the TATA element. When TFIID was bound to the E4 promoter in the presence of ATF (and ATF recognition elements upstream of the TATA element), the footprint of TFIID was found to extend downstream from the TATA element to +35 . Once human TFIID had been induced to make contact downstream to +35 on the E4 promoter, the activator could be competed away with an oligonucleotide leaving intact the large TFIID footprint with the downstream contact. A new structural feature was revealed when the ATF was competed away. In the region between -60 and -85 , hypersensitive DNase I cut sites were apparent on the transcribed strand. Structural features similar to those induced by ATF are apparent for all of the footprints that were produced by the immobilized Drosophila TFIID (Fig. 1). The similarity between the activator-dependent features of TFIID on the E4 promoter and those that are intrinsic to the complex that we have analyzed raises the possibility that the DNA sequence of the $h s p 26$, hsp 70, and histone H3 promoters may bypass the need for an activator to induce this conformational change. This would not necessarily activate transcription but could eliminate this conformational change as a regulatory step in the pathway toward activation of these three promoters.

\section{Materials and methods \\ Protein fraction preparation and mobility retardation assay}

Nuclear extract preparation and subsequent fractionation on DEAE and phosphocellulose (P11) columns were performed as described by Purnell and Gilmour (1993). The phosphocellulose fraction served as crude TFIID in the mobility retardation assays. These assays were performed as described by Purnell and Gilmour (1993).

\section{Immunopurification and immobilization of TFIID}

Immunopurification of TFIID from the $0.5 \mathrm{M}$ phosphocellulose fraction (Purnell and Gilmour 1993) was performed at $4^{\circ} \mathrm{C}$, and all tips and tubes were siliconized. Sixty-five micrograms of protein from the $0.5 \mathrm{M}$ phosphocellulose fraction $(34 \mu \mathrm{l})$ was incubated with $18 \mu$ l of monoclonal anti-TBP 14C2-F4 hybridoma supernatant for $1 \mathrm{hr}$ on ice. Eighteen microliters of a 50/50 slurry of protein G-Sepharose in $100 \mathrm{mM} \mathrm{KCl-HEGMN} \mathrm{was}$ then added to the mixture and allowed to bind for an additional hour with gentle rocking. HEGMN is $25 \mathrm{mM}$ HEPES ( $\mathrm{pH} 7.6$ ), $0.1 \mathrm{~mm}$ EDTA, $12.5 \mathrm{~mm} \mathrm{MgCl}, 10 \%$ glycerol, $0.1 \%$ NP. 40,1 $\mathrm{mM}$ DTT, and $0.1 \mathrm{mM}$ PMSF. The bound protein was then spun down at $2000 \mathrm{rpm}$ in an Eppendorf model 5415C microcentrifuge for $4 \mathrm{~min}$ and washed four times with 1.5-ml aliquots of $100 \mathrm{~mm} \mathrm{KCl-HEGMN}$. The slurry was transferred to a fresh tube, and the beads were washed twice with $1.5 \mathrm{ml}$ of binding buffer. The supernatant was then removed to leave a 20- $\mu$ l volume of beads and buffer. Binding buffer consisted of $10 \mathrm{mM}$ HEPES (pH 7.6), $5 \mathrm{mM} \mathrm{MgCl}_{2}, 0.8 \mathrm{~mm}$ DTT, $0.1 \mathrm{mM}$ PMSF, 90 $\mathrm{mM} \mathrm{KCl}, 5 \mathrm{ng} / \mu \mathrm{l}$ poly[d(C/G)], and $10 \%$ glycerol.

\section{SDS-PAGE analysis of immunoprecipitated TFIID}

The total immunoprecipitate prepared using monoclonal antibody was resuspended in SDS loading buffer and boiled prior to electrophoretic separation. Immunopurified TFIID prepared in parallel was treated with $1 \mathrm{M}$ guanidine- $\mathrm{HCl}$ in $100 \mathrm{mM} \mathrm{KCl-}$ HEGMN to elute the TAFs from the antibody-bead complex. Two 50- $\mu \mathrm{l}$ aliquots of $1 \mathrm{M}$ guanidine were incubated with $10 \mu \mathrm{l}$ of bed volume TFIID beads for $10 \mathrm{~min}$, and the supernatants were removed. The guanidine was diluted with an equal volume of $0 \mathrm{M} \mathrm{KCl}-\mathrm{HEGMN}$ followed by the addition of 0.25 volumes of trichloroacetic acid (TCA). TCA precipitates were spun for 30 min at $14,000 \mathrm{rpm}$ in an Eppendorf model $5415 \mathrm{C}$ microcentrifuge, and the pellets were then washed with $500 \mu \mathrm{l}$ of ice-cold acetone and resuspended in SDS loading buffer. Proteins remaining bound to the beads were washed with $0 \mathrm{M} \mathrm{KCl-}$ HEGMN and resuspended in SDS loading buffer for electrophoresis.

\section{DNA fragments}

The hsp 70, hsp26, and histone $\mathrm{H} 3$ promoter fragments were derived from subclones described previously (Gilmour et al. 1988 , 1990). Fragments were radiolabeled by using either polynucleotide kinase or Klenow polymerase. Radiolabeled fragments from each promoter were gel-isolated, ethanol-precipitated, and quantified before use in binding reactions.

\section{DNase I footprinting with immobilized TFIID}

Immobilized TFIID equilibrated with binding buffer was prepared in a total volume of $20 \mu \mathrm{l}$ as described above. Thirty microliters of binding buffer containing 100,000 Cherenkov counts of radiolabeled DNA fragment and $2 \mu \mathrm{g}$ of HaeIII-cut Escherichia coli DNA was added to the beads to give a total reaction volume of $50 \mu \mathrm{l}$. The binding reaction was allowed to rock at $25^{\circ} \mathrm{C}$ for $1 \mathrm{hr}$, and unbound DNA was removed with the supernatant following microcentrifugation at $2000 \mathrm{rpm}$ for 4 min. Three washes with $1.5 \mathrm{ml}$ of ice-cold binding buffer were performed, followed by an additional wash with $1.5 \mathrm{ml}$ of DNase I footprinting mix ( $150 \mathrm{~mm}$ potassium glutamate, $10 \mathrm{~mm}$ Tris at $\mathrm{pH} 7.9,10 \mathrm{~mm} \mathrm{MgCl} 2,1 \mathrm{~mm}$ DTT, $0.1 \mathrm{~mm}$ EDTA, $0.1 \%$ NP-40, $0.1 \mathrm{mM}$ PMSF, and $2 \mathrm{mM}$ spermidine). The supernatant was then removed to leave a total volume of $50 \mu \mathrm{l}$, and $50 \mu \mathrm{l}$ of $10 \mathrm{mM} \mathrm{MgCl}_{2}, 5 \mathrm{mM} \mathrm{CaCl}_{2}$ containing 0.2 units of DNase I was then added. The 100- $\mu$ l digestion was allowed to proceed for 30 sec and was terminated by the addition of $100 \mu \mathrm{l}$ of $3.1 \mathrm{M}$ $\mathrm{NH}_{4} \mathrm{OAc}, 238 \mu \mathrm{g} / \mathrm{ml}$ of yeast tRNA. Samples were then phenol extracted and ether extracted, and the DNA was precipitated for analysis on DNA sequencing gels. 


\section{Hydroxyl radical interference}

Radiolabeled DNA promoter fragments were modified by hydroxyl radicals for $2 \mathrm{~min}$ as described by Tullius and Dombroski (1986). Modified DNAs were then isobutanol extracted two times, ether-extracted, and ethanol precipitated for use as input DNA in binding reactions. Immunopurified TFIID in $20 \mu \mathrm{l}$ of binding buffer was mixed with $30 \mu \mathrm{l}$ of binding buffer containing 100,000 Cherenkov counts of hydroxyl radical-treated DNA and $2 \mu \mathrm{g}$ of HaellI-cut $E$. coli DNA. The binding reactions proceeded for $1 \mathrm{hr}$ at $25^{\circ} \mathrm{C}$ with gentle rocking. Bound promoter fragments were collected following a brief centrifugation, and the supernatant containing unbound promoter fragments was removed and ethanol precipitated as free DNA. The beads were washed three times with ice-cold binding buffer to remove nonspecifically bound DNAs. DNA remaining associated with TFIID was recovered by phenol-extracting the suspension of Sepharose beads and ethanol-precipitating the aqueous phase. Recovered DNA was quantified by Cherenkov counting and resuspended in formamide loading dye. Equal amounts of this bound DNA were electrophoresed in parallel with free DNA, input DNA, and G/A markers derived from the original promoter fragments.

\section{$S A A B$}

The SAAB protocol was performed as described by Blackwell and Weintraub (1990), with the following modifications. Two oligonucleotides were synthesized that could anneal and be extended to give the Drosophila hsp 70 promoter from position -39 to +36 , relative to the transcription start site (see Fig. 2). The 2 oligonucleotides were annealed, extended, and amplified with Taq polymerase, dNTPs, and primers $A$ and $B$ to give double-stranded DNA fragments. The resulting DNA contained the randomized initiator, restriction sites that correspond to EcoRI and $B a m H I$, and sequences that correspond to primers $A$ and $B$. This DNA was amplified by PCR with primers A and B and Taq polymerase, and the DNA was then radioactively end-labeled with kinase and $\left[{ }^{32} \mathrm{P}\right] \mathrm{ATP}$. Labeled template $(100,000 \mathrm{cpm})$ was incubated with $3.75 \mu \mathrm{l}$ of the P11 TFIID fraction in a 62.5- $\mu$ l binding reaction volume. Other components of the binding reaction included $10 \mathrm{~mm}$ HEPES ( $\mathrm{pH} 8.0$ ), $5 \mathrm{~mm} \mathrm{MgCl}_{2}, 20 \mathrm{ng} / \mu \mathrm{l}$ of HaeIII-digested E. coli DNA, $0.8 \mathrm{~mm}$ DTT, $90 \mathrm{~mm} \mathrm{KCl}, 1 \mathrm{~mm}$ PMSF, and $10 \%$ glycerol. Binding occurred at room temperature for $40 \mathrm{~min}$, and then the reaction $\mathrm{mix}$ was subjected to gel electrophoresis. Bound and unbound DNAs were then isolated (Blackwell and Weintraub 1990) and amplified by PCR. The amplified DNA was subjected to additional rounds of selection by TFIID, sequenced, or cloned. PCR-amplified DNA pools from each round were directly sequenced using primers $A$ and $B$ and Sequenase (U.S. Biochemical) as described by Blackwell and Weintraub (1990). Clones were isolated from round 5 by digesting the PCR-amplified DNA pool with EcoRI and BamHI and then inserting the fragment into comparably cut pUC13. Sequence analysis of isolated clones was performed using the TaqTrack sequencing system (Promega) and either the reverse sequencing primer (5'-AACAGCTATGACCATGATTACG) or sequencing primer (5'-GTTGTAAAACGACGGCCAGT).

\section{$P C R$}

PCR amplification was carried out in an ERICOMP thermocycler for 20 cycles of a three-step program: Step 1 was a $1-\mathrm{min}$ incubation at $95^{\circ} \mathrm{C}$; step 2 was a 1 -min incubation at $45^{\circ} \mathrm{C}$; and step 3 was a $30-\mathrm{sec}$ incubation at $72^{\circ} \mathrm{C}$. The primers used for amplification were the following: primer A $\left(5^{\prime}\right.$-GATGGGATCCATTAG) and primer B (5'-GATCGAATTCCGGAG). PCR products were ethanol-precipitated and purified on an $8 \%$ polyacrylamide gel.

\section{Acknowledgments}

We thank Robert Weinzierl and Robert Tjian for the generous gift of monoclonal antibody 14C2-F4 against TBP and Stephen Smale for providing information prior to publication. We also thank D. Taxman, S. Emanuel, and the other members of the Gilmour laboratory for helpful discussions. This work was supported by grant GM47477 from the National Institutes of Health and an American Cancer Society Junior Faculty Award to D.S.G. Sigma Xi grant-in-aid of research awards were also provided to both B.A.P. and P.A.E. The footprinting and interference analyses were performed by P.A.E., and the SAAB analysis was performed by B.A.P; therefore, both should be considered primary authors.

The publication costs of this article were defrayed in part by payment of page charges. This article must therefore be hereby marked "advertisement" in accordance with 18 USC section 1734 solely to indicate this fact.

\section{References}

Anderson, K.V. and J.A. Lengyl. 1984. Histone gene expression in Drosophila development: Multiple levels of gene regulation. In Histone genes (ed. G.S. Stein, J.L. Stein, and W.F. Marzluff|, p. 135-161. John Wiley \& Sons, New York.

Arkhipova, I.R. and Y.V. Ilyin. 1991. Properties of promoter regions of $\mathrm{mdg} 1$ Drosophila retrotransposon indicate that it belongs to a specific class of promoters. EMBO J. 10: 11691177.

Bartholomew, B., D. Durkovich, G.A. Kassavetis, and E.P. Geiduschek. 1993. Orientation and topography of RNA polymerase III in transcription complexes. Mol. Cell. Biol. 13: $942-952$.

Bell, S.P., C.S. Pikaard, R.H. Reeder, and R. Tjian. 1989. Molecular mechanisms governing species-specific transcription of ribosomal RNA. Cell 59: 489-497.

Biggin, M.D. and R. Tjian. 1988. Transcription factors that activate the Ultrabithorax promoter in developmentally staged extracts. Cell 53: 699-711.

Blackwell, T.K. and H. Weintraub. 1990. Differences and similarities in DNA-binding preferences of MyoD and E2A protein complexes revealed by binding site selection. Science 250: 1104-1110.

Breathnach, R. and P. Chambon. 1981. Organization and expression of eucaryotic split genes coding for proteins. Annu. Rev. Biochem. 50: 349-383.

Bucher, P. 1990. Weight matrix descriptions of four eucaryotic RNA polymerase II promoter elements derived from 502 unrelated promoter sequences. J. Mol. Biol. 212: 563-578.

Buratowski, S., S. Hahn, L. Guarente, and P.A. Sharp. 1989. Five intermediate complexes in transcription initiation by RNA polymerase II. Cell 56: 549-561.

Carcamo, J., L. Buckbinder, and D. Reinberg. 1991. The initiator directs the assembly of a transcription factor IID-dependent transcription complex. Proc. Natl. Acad. Sci. 88: 8052-8056.

Cherbas, L. and P. Cherbas. 1993. The arthropod initiator: The capsite consensus plays an important role in transcription. Insect Biochem. Mol. Biol. 23: 81-90.

Chiang, C.-M., H. Ge, Z. Wang, A. Hoffman, and R.G. Roeder. 1993. Unique TATA-binding protein containing complexes 
and cofactors involved in transcription by RNA polymerases II and III. EMBO I. 12: 2749-2762.

Comai, L., N. Tanese, and R. Tjian. 1992. The TATA-binding protein and associated factors are intergral components of the RNA polymerase I transcription factor, SL1. Cell 68: $965-976$.

Craig, E.A. 1985. CRC Crit. Rev. Biochem. 18: 239-280.

Du, H., A.L., Roy, and R.G. Roeder. 1993. Human transcription factor USF stimulates transcription through the initiator elements of the HIV-1 and Ad-ML promoters. EMBO J. 12: $501-511$.

Dynlacht, B.D., T. Hoey, and R. Tjian. 1991. Isolation of coactivators associated with the TATA-binding protein that mediate transcriptional activation. Cell 66: 563-576.

Emanuel, P.A. and D.S. Gilmour. 1993. TFIID recognizes DNA sequences downstream of the TATA element in the hsp 70 heat shock gene. Proc. Natl. Acad. Sci. 90: 8449-8453.

Fridell, Y.-W.C. and L.L. Searles. 1992. In vivo transcriptional analysis of the TATA-less promoter of the Drosophila melanogaster vermillion gene. Mol. Cell. Biol. 12: 4571-4577.

Gilmour, D.S., T.J. Dietz, and S.C.R. Elgin. 1988. TATA boxdependent protein-DNA interactions are detected on heat shock and histone gene promoters in nuclear extracts derived from Drosophila melanogaster embryos. Mol. Cell. Biol. 8: 3204-3214.

- 1990. UV-cross-linking identifies four polypeptides that require the TATA box to bind to the Drosophila hsp70 promoter. Mol. Cell. Biol. 10: 4233-4238.

Hahn, S., S. Buratowski, P.A. Sharp, and L. Guarente. 1990. Yeast TATA-binding protein TFIID binds to TATA elements with both consensus and nonconsensus DNA sequences. Proc. Nat1. Acad. Sci. 86: 5718-5722.

Hawley, D.K. and R.G. Roeder. 1987. Functional steps in transcription initiation and reinitiation from the major late promoter in a HeLa nuclear extract. J. Biol. Chem. 262: 34523461 .

Hayes, J.J. and T.D. Tullius. 1989. The missing nucleoside experiment: A new technique to study recognition of DNA by protein. Biochemistry 28: 9521-9527.

Hoey, T., R.O.J. Weinzierl, G. Gill, J.-L. Chen, B.D. Dynlacht and R. Tjian. 1993. Molecular cloning and functional analysis of Drosophila TAF110 reveal properties expected of coactivators. Cell 72: 247-260.

Horikoshi, M., T. Hai, Y. Lin, M. Green, and R.G. Roeder. 1988. Transcription factor ATF interacts with the TATA factor to facilitate establishment of a preinitiation complex. Cell 54: 1033-1042.

Hultmark, D., R. Klemenz, and W. Gehring. 1986. Translational and transcriptional control elements in the untranslated leader of the Heat-shock gene hsp22. Cell 44: 429-438.

Javahery, R., A. Khachi, K. Lo, B. Zenzie-Gregory, and S.T. Smale. 1994. DNA sequence requirements for transcriptional initiator activity in mammalian cells. Mol. Cell. Biol. 14: 116-127.

Jarrell, K.A. and M. Meselson. 1991. Drosophila retrotransposon promoter includes an essential sequence at the initiation site and requires a downstream sequence for full activity. Proc. Natl. Acad. Sci. 88: 102-104.

Kadonaga, J.T. 1990. Assembly and disassembly of the Drosophila RNA polymerase II complex during transcription. $I$. Biol. Chem. 265: 2624-2631.

Kassavetis, G.A., B.R. Braun, L.H. Nguyen, and E.P. Geiduschek. 1990. S. cerevisiae TFIIIB is the transcription initiation factor proper of RNA polymerase III, while TFIIIA and TFIIIC are assembly factors. Cell 60: 235-245.

Kassavetis, G.A., C.A.P. Joazeiro, M. Pisano, E.P. Geiduschek,
T. Colbert, S. Hahn, and J.A. Blanco. 1992. The role of the TATA-binding protein in the assembly and function of the multisubunit yeast RNA polymerase III transcription factor, TFIIIB. Cell 71: 1055-1064.

Kim, J.L., D.B. Nikolov, and S.K. Burley. 1993a. Co-crystal structure of TBP recognizes the minor groove of a TATA element. Nature 365: 520-527.

Kim, Y., J.H. Geiger, S. Hahn, and P.B. Sigler. 1993b. Crystal structure of a yeast TBP/TATA-box complex. Nature 365: 512-520.

Lablanc, B., C. Read, and T. Moss. 1993. Recognition of the Xenopus ribosomal core promoter by the transcription factor xUBF involves multiple HMG box domains and leads to an $x U B F$ interdomain interactions. $E M B O J$. 12: 513-525.

Lee, H., K.W. Kraus, M.F. Wolfner, and J.T. Lis. 1992. DNA sequence requirements for generating paused polymerase at the start of hsp 70. Genes \& Dev. 60: 284-295.

Lindquist, S. 1986. The heat-shock response. Annu. Rev. Biochem. 55: 1151-1191.

Nakajima, N., M. Horikoshi, and R.G. Roeder. 1988. Factors involved in specific transcription by mammalian RNA polymerase II: Purification, genetic specificity, and TATA boxpromoter interactions of TFIID. Mol. Cell. Biol. 8: 40284040.

Perkins, K.K., G.M. Dailey, and R.T. Tjian. 1988. In vitro analysis of the Antennapedia P2 promoter: Identification of a new Drosophila transcription factor. Genes \& Dev. 2: 16151626.

Pikaard, C.S., B. McStay, M.C. Schultz, S.P. Bell, and R.H. Reeder. 1989. The Xenopus ribosomal gene enhancers bind an essential polymerase I transcription factor, xUBF. Genes \& Dev. 3: 1779-1788.

Pugh, B.F. and R. Tjian. 1991. Transcription from a TATA-less promoter requires a multisubunit TFIID complex. Genes \& Dev. 5: 1935-1945.

1992. Diverse transcriptional functions of the multisubunit eucaryotic TFIID complex. J. Biol. Chem. 267: 679-682.

Purnell, B.A. and D.S. Gilmour. 1993. Contribution of sequences downstream of the TATA element to a protein/ DNA complex containing the TATA-binding protein. Mol. Cell. Biol. 13: 2593-2603.

Roy, A.L., M. Meisterernst, P. Pognonec, and R.G. Roeder. 1991. Cooperative interaction of an initiator-binding transcription initiation factor and the helix-loop-helix activator USF. $\mathrm{Na}$ ture 354: 245-248.

Roy, A.L., S. Malik, M. Meisterernst, and R.G. Roeder. 1993. An alternative pathway for transcription initiation involving TFII-I. Nature 365: 355-359.

Sawadogo, M. and R.G. Roeder. 1985. Interaction of a genespecific transcription factor with the adenovirus major late promoter upstream of the TATA box region. Cell 43: 165 175

Seto, E., Y. Shi, and T. Shenk. 1991. YY1 is an initiator sequence-binding protein that directs and activates transcription in vitro. Nature 354: 241-245.

Smale, S.T. 1994. Core promoter architecture for eucaryotic protein-coding genes. In Transcription: Mechanisms and regulation. (ed. R.C. Conaway and J.W. Conaway), pp. 63-81. Raven Press, New York.

Smale, S.T. and D. Baltimore. 1989. The initiator as a transcription control element. Cell 57: 103-113.

Smale, S.T., M.C. Schmidt, A.J. Berk, and D. Baltimore. 1990. Transcriptional activation by $\mathrm{Spl}$ as directed throught TATA or initiator: Specific requirement for mammalian transcription factor IID. Proc. Natl. Acad. Sci. 87: 45094513. 
Purnell et al.

Soeller, W.C., S.J. Poole, and T. Komberg. 1988. In vitro transcription of the Drosophila engrailed gene. Genes \& Dev. 2: $68-81$.

Sypes, M.A. and D.S. Gilmour. 1994. Protein/DNA crosslinking of a TFIID complex reveals interactions downstream of the transcription start. Nucleic Acids Res. (in press).

Taggart, A.K.P., T.S. Fisher, and B.F. Pugh. 1992. The TATAbinding protein and associated factors are components of pol III transcription factor TFIIIB. Cell 71: 1015-1028.

Tullius, T.D. and B.A. Dombroski. 1986. Hydroxyl radical "Footprinting": High-resolution information about DNAprotein contacts and application to Lambda repressor and Cro protein. Proc. Natl. Acad. Sci. 83: 5469-5473.

Van Dyke, M.W., R.G. Roeder, and M. Sawadogo. 1988. Physical analysis of transcription preinitiation complex assembly on a class II gene promoter. Science 241: 1335-1338.

Vazquez, J., D. Pauli, and A. Tissieres. 1993. Transcriptional regulation in Drosophila during heat shock: A nuclear runon analysis. Chromosoma 102: 233-248.

Weinzierl, R.O.J., B.D. Dynlacht, and R. Tjian. 1993. Largest subunit of Drosophila transcription factor IID directs assembly of a complex containing TBP and a coactivator. Nature 362: $511-517$.

White, R.J. and S.P. Jackson. 1992. Mechanism of TATA-binding protein recruitment to a TATA-less class III promoter. Cell 71: 1041-1053.

Zawel, L. and D. Reinberg. 1993. Initiation of transcription by RNA polymerase II: A multi-step process. Prog. Nucleic Acids Res. Mol. Biol. 44: 67-108.

Zenzie-Gregory, B., A. O'Shea-Greenfield, and S.T. Smale. 1992. Similar mechanisms for transcription initiation mediated through a TATA box or an initiator element. $J$. Biol. Chem. 267: 2823-2830.

Zhou, Q., P.M. Lieberman, T.G. Boyer, and A.J. Berk. 1992. Holo-TFIID supports transcriptional stimulation by diverse activators and from a TATA-less promoter. Genes \& Dev. 6: 1964-1974. 


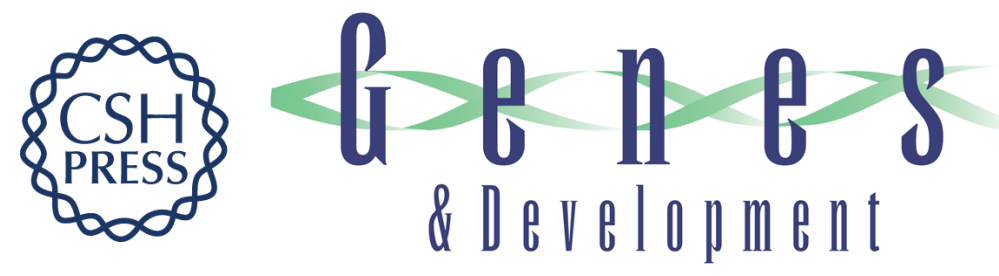

\section{TFIID sequence recognition of the initiator and sequences farther downstream in Drosophila class II genes.}

B A Purnell, P A Emanuel and D S Gilmour

Genes Dev. 1994, 8:

Access the most recent version at doi:10.1101/gad.8.7.830

References This article cites 57 articles, 23 of which can be accessed free at:

http://genesdev.cshlp.org/content/8/7/830.full.html\#ref-list-1

License

Email Alerting

Service right corner of the article or click here.

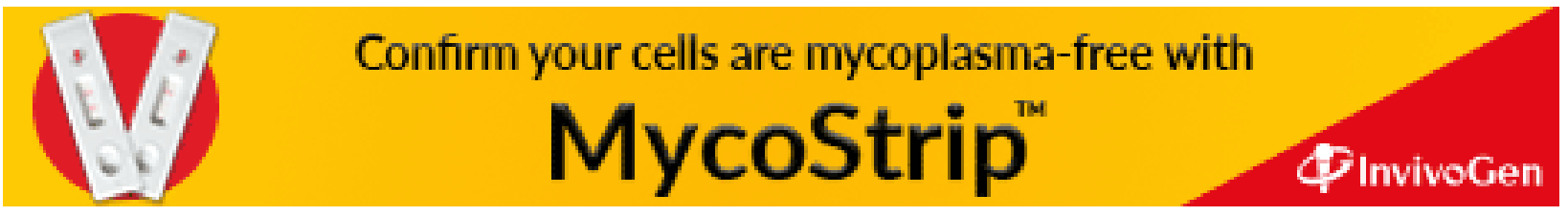

